SHS Web of Conferences 7, 02010 (2014)

DOI: $10.1051 /$ shsconf $/ 20140702010$

(C) Owned by the authors, published by EDP Sciences, 2014

\title{
Study on the Strategy of Transforming Students with Learning Difficulties in Polytechnic Schools
}

\author{
Cui Fan \\ Pingdingshan Institute of Education, 467000 Pingdingshan Henan, China
}

\begin{abstract}
As demand of China's social construction increasing and as the development of vocational education, polytechnic school plays an increasing important part, which, on the other hand, constitutes unprecedented challenges to the teaching in polytechnic schools. Most students, in the aspect of vocational education, are those from middle schools who have difficulties in their study. These students are entitled "Underachievers". They are short in intellectual study and poor in curricular foundations. Teaching tasks cannot be satisfactorily accomplished in many of the polytechnic schools for the increasing number of underachievers. What have been harnessing the polytechnic school development is the poor study effect of these students. In this article, the internal reason of character and the external reason of social influence are analyzed as the cause that contributes to learning difficulties. And this article offers a pragmatic set of ideas for underachiever transformation.
\end{abstract}

Keywords. polytechnic school; learning difficulties; underachievers; countermeasures

In society and in common sense, vocational school students are those who have difficulties in learning well. And they are discriminated in society. Nowadays, there is widespread negative evaluation, or rather, contemptuous disregard, from different sectors of society upon polytechnic school students. However, it is worth noticing that this is a group of 16 to 19 -year-old teenagers who has not been psychologically independent. Discrimination may create other problems, such as psychological problems, in them. Many of them are sensitive, brittle and always concerned about attitudes and evaluations from others. So many of them take pride in successfully challenging the authoritative figure in a community. They oppose merely for opposition. All these factors make them resistant to teacher's help and refuse even to alter themselves. As a result, they are constantly "underachievers".

Long loitering outside the classroom, "underachievers" have long been unable to get others' recognition and praise and unable to experience the joy of success. So they tend to have a sense of subnormality, namely, acquired helplessness. They would be accompanied by this sense and psychological condition after they step out of school and later enter the society, which is not fair for them. So educators should start solving this problem by offering underachievers cares and concerns, in order to make them develop healthily.

\section{Research to origin of the problem}

China's vocational education covers a ragged path. A very important aspect is that the students generally have great trouble in study, weariness haunting many of them. This phenomenon constitutes This is an Open Access article distributed under the terms of the Creative Commons Attribution License 4.0, which permits unrestricted use, distribution, and reproduction in any medium, provided the original work is properly cited. 
immense hinderance to China's vocational education. And it is even threatening the survival of many polytechnic schools. So polytechnic schools are facing a spiny problem how to eliminate leaning difficulties and enhance learning capacity in order to offer eligible labor to enterprises. There are many reasons for learning difficulties. They are as follows:

\subsection{Poor knowledge foundation and low learning capacity}

Newly recruited vocational school students are generally deficient in theoretical knowledge foundation and weak in learning capacity. They are students who got low marks in primary high school. As a result, they failed in entering secondary high school. Meanwhile, they have learning from difficulties to different extends. Polytechnic school students nowadays are those who fail in carefully learning knowledge in such subjects as Chinese, mathematics, English, chemistry, physics, etc. And they are weak in learning. Such students, once they enter a polytechnic school after graduating from middle school, would be faced with a lot of difficulties as curricular contents and methodology changes. They are confronted with large amounts of professional courses in vocational school. These courses are associated with middle school knowledge on one hand and have their own vocational characteristics on the other hand. All the above elements aggravate the trouble with vocational school students who have had neither high scores in secondary high school nor good learning habits.

\subsection{Vague learning motivation and misconduct in learning attitude}

In psychology, learning motivation refers to intention or personal desire, psychological demands, an attempt or intrinsic strength to reach the goal. "I want to learn" is the precondition of active learning. However, a considerable amount of vocational school students do not exactly know why they attend school, which can be regarded as vague learning motivation. These students lack intrinsic demand for learning. They learn passively. Step-backs are common because they lack desire for knowledge.

Some students have been regarded as underachievers ever since their primary high school period, which severely corroded their desire and enthusiasm for learning, and which deprived them of confidence. They are made, by the muddle-along attitude, to engage themselves in such alternative activities as playing video games, communications, etc.

\subsection{Lack of good learning habit and effective learning methods}

No external supervisory control needed, habit is the automation of behaviours. Firm "dynamic stereotype" takes shape both physically and mentally once excellent learning habit is developed. Vocational school students are not due to take the University Entrance Exam so that there is no sense of stress in their mind, which lead to insufficient drive. The students are very indolent, strongly dependent and passive in learning. They neither preview nor review. They are not focused on class and plagiarize homework or simply brush it aside. Frequently do they fail and constantly do they cheat in the exams. They even truant practice courses quite often. They do not have thorough learning schedule and are always aimless. They do not know the knowledge of truth. Nor do they want to know. In other words, they lack impetus. They play with their handsets and chat in self-study courses. And they idle about in their spare time. The bad learning attitudes and habits above are caused not only by former experiences but also by the absence of learning objectives and perplexity of the future.

\section{Study on underachiever transformation strategy}

The above reasons lead to learning difficulties of vocational school students. There is a widely existing phenomenon that the students are reluctant to learn and that the teachers are reluctant to teach when they are faced with difficulties. And this severely affected the teaching quality in polytechnic schools. Once a student fails to learn due knowledge and skills during his school years, he/she would 
be unable to put his/her constructive talent into practical use promptly. In this way, he/she would become a burden of both him/herself and the society. According to scholastic analysis, study on underachiever transformation strategy can generally be divided into two steps, first endopathic factor and second exopathic factor.

\subsection{Advice for students}

\subsubsection{Adjust objectives to motivate learning}

Most vocational school students, when they choose polytechnic school, are not clear about their career direction or what they really need. It is not willingly that they made the choice. No other choice could be made because of their poor marks. After entering polytechnic school, they cannot adapt to new learning situation and fail in switching from learning method for exam-originated education to that for vocational education. They did not make their academic foundation solid in their primary high school period so that lasting effects are still troubling them. This makes the students gradually lose confidence in learning. Some of them come to school not to learn anything but to kill time.

What to learn is determined by learning objective while objective originates in orientation of life value. Therefore, vocational school students ought to adjust their learning objective when faced with new learning situations. First, vocational school students ought to be clear that vocational education is capability-centered and employment-oriented education form. It mainly trains pragmatic labor and its value pursuit is useful, practical and functional. Second, recent vocational education ought to undertake the task for educating high-skilled labor. Studying in vocational schools is also an indispensable sequence of social construction.

\subsubsection{Enhance self-control and self-management ability}

During learning, polytechnic school students are easily affected by the circumstance and their own mood and they are vulnerable to seize full control of their mind and behaviour. They bear casual attitude towards life and study without thinking about scheduling for the future. Even if there is a schedule, it is usually poorly performed. They cannot persevere. These are all performances of selfcontrol shortage. How to boost their self-control abilities? The author considers it takes selfmanagement to develop high self-control abilities.

First of all, self-management on class can be realized through "three consciousness". One of them is the students' subject consciousness. They should be clear that they are the subject in learning activities. They ought to ponder actively and speak out on class and participate in learning activities on class. Another consciousness is that the students ought to have sense of efficiency. They ought to overcome slack defects, enhance learning efficiency and manage to finish the tasks on class that is due to be finished on class. The third consciousness is that the students ought to have sense of self-control. They should adjust both their mind and their body to the best state, concentrate on the teacher's instructions and do nothing unassociated with classroom learning.

\subsubsection{Overcome crisis while growing up and improve interpersonal relationship}

Polytechnic school students constantly encounter perplexity and frustrations caused by various crises. To deal with this problem, they should first brave it out, orient their mind with optimistic mentality and be masters of themselves, without being affected by mood. Second, they should also be clear that crisis is sometimes an opportunity, in which man mature by dealing with pressure. This is because man can profoundly sense the grittiness of vitality while struggling with and conquering difficulties. Only in the process of dealing with difficulties can human beings find his own shortcomings and then learn actively so as to improve themselves constantly.

Contact people with positive energy and increase pleiotropic interpersonal communications. Outstanding communication skills can not only enrich the students' life but also help them step into 
society and begin their occupational career. It is also an important skill of correct self-cognition. But in reality, factors like dislocation of family education, backward management system, improper education methods and bad social atmosphere nurture such undesirable tendency as self-centering, self-enclosing, indifference, hostility and chivalrous righteousness, etc. Thus communication difficulties emerge.

\subsection{Advice for teachers}

\subsubsection{Respect your students and be a good mentor}

In polytechnic school, it is especially important for teachers to transform their idea. Teaching is an activity that stresses multilateral collaborations. Perfect and tacit interaction between teacher and students creates even better learning effect. The teacher-student relationship must be based on mutual trust. Teachers should first win students' trust with personal charisma. In polytechnic school, a student is enthusiastic about a certain subject usually because he/she likes the teacher of this subject. Favorable impression of a subject deriving from that of its teacher, personal charisma proves crucial.

Of course, a certain distance ought to be reserved in teacher-student relationship. Rules ought not to be broken while gaining the students' trust. Intimacy ought to be conserved at a reasonable degree. Over-intimacy undermines teacher's authority while under-intimacy hinders communications between teachers and students. Teachers ought to be a mentor who constrains and gives care both at due time, and be flexible without crashing the bottom line.

\subsubsection{Create opportunities for enhancing the students' confidence}

Psychological research shows that a man with confidence has infinite power. As Maslow said, confidence changes people's opinion on the world round him. It liberates people. And people subsequently have greater spontaneity and creativity. Thus teachers ought to show more concern about underachievers on class. While educating and transforming underachievers, teachers should also create more opportunities for their success in order to enhance their confidence for learning. Therefore, teachers should understand the characteristic of the underachievers and scheme out teaching plans based on their situations. Teachers could start with easily achievable targets and set higher targets after the former one is achieved through the students' efforts. Learning interest and enthusiasm can be actuated through these stratified targets.

\subsubsection{Attach importance to teaching level improvements}

Teaching has definite rules but infinite methods. Polytechnic school teachers must carefully study the actual need of their students and what exactly their interest is so as to work out more targeted teaching plans and adjust their teaching contents accordingly. Teaching design and teaching targets ought to be directed by enterprise demands and occupational requirements. Connect theory teaching with skill training at a "necessary and sufficient" degree.

Teachers should also study teaching methods. During "underachiever" transformation, teachers should teach learning strategy systematically and train the students to use the strategy. Teachers ought to give specific instructions when students encounter troubles while learning the strategy. Learning can be greatly motivated on condition that students forwardly use practical learning strategy under the teacher's guidance on class. So it is an effective method to guide the "underachievers" to master certain learning strategies, which has been proven by large amounts of practice.

\subsection{Advice for schools}

\subsubsection{Strengthen the occupation career planning education}


During an interview, the author saw the fear, in polytechnic school students, for the uncertainty of their future and he discovered their ignorance on how to make a plan for their study. Obviously, little has been done in career planning guidance for current students in polytechnic schools. These students must master a whole set of scientific career planning strategy as long as they want to successfully work out their career plan, reasonably schedule for their future and later find a suitable job. Therefore, polytechnic schools ought to set up special courses that provide hierarchical, targeted and systematic career plan guidance. Establish scientific career plan course system according to the characteristics of different phases in their occupational development. Make the students able to systematically master career plan theory and methodology and develop ability and awareness in occupational development. By learning career planning, students can have more practical attitude on employment issues. And they can have a comprehensive understanding of occupation and employment so that they can define their positions. Thinking about and focusing on long-term career planning also helps to arouse consciousness that high eligibility is in urgent need. Thus students learn with stronger learning objectives.

\subsubsection{Build a platform for activities and create educational atmosphere}

The school recreational activities should be able to attract students to participate in. Aiming at promoting quality, recreational activities create a good educational environment in lively, entertaining activities. They are not abstract preaching or stereotyped show-hows. Nor are they simple indoctrination. Through these activities, students acknowledge naturally in such aspects as mode of thinking, psychological activities and social values, etc. In this way, psyche maturing is accomplished. This educational process is carried out through osmosis, which is more acceptable.

School should build a stage for the students to show themselves and influence other students through the power of example. And a relaxing atmosphere ought to build in order to meet the students' need of development, self-improvement and self-realization, etc. In this way, they can achieve psychological balance and health.

\subsubsection{Strengthen the contact between the teachers and parents}

Family is the initial environment in which students grow up. Therefore, family is as responsible for a student's learning difficulties as the school is. Family education ideas ought to be corrected and family education quality ought to be improved. Cooperation between families and schools is necessary in moral education. Parents are first teachers of their children. They ought to educate their children not only through oral preaching but also by osmosis. Then can actively participate in school education, and respect the views of teachers. On one hand, teachers get more useful information, through communications with parents. And this allows the teachers to better understand the cause of students' learning difficulties. On the other hand, parents can understand, in detail, the teaching targets of the school and the teachers. Thus parents would give more support to school.

\section{Conclusion}

Polytechnic school underachievers have two protruding features. One is that they are large in number and take up large proportions. The other is that they are poor in knowledge foundation. Parent, teacher and school are all crucial elements in the process of transforming underachievers. Difficulties in learning are caused not only by intellect but also by other factors. Modern educational psychology research confirmed that there is an integrated psychological structure functioning in learning activities. Two of its key points are cognitive factors and dynamic factors. Cognitive factors include analyzing and abstracting information and reacting to it. Dynamic factors include emotion, stance, demand and idea. Reacting activities, in cognitive factors, have such functions as initiation, orientation, guidance, maintenance, adjusting and strengthening. 
The effect of non-intelligence factors determines that we must start from various aspects to transform underachievers. For example, conventional teaching notions and methods ought to be renovated. Convert "I am taught" to "I want to learn". Teachers ought to design suitable atmosphere, according to the students' situation and teaching contents, for students' autonomous learning in order to stimulate their enthusiasm.

\section{References}

1. Lee H., et al. Psychological Features and Education of Underachievers[M]. Beijing: Beijing Science, 1987:10-75.

2. Wang Z., et al. Care for Each Student's development: Transformation Theory and Strategy for "Underachievers"[M]. Shandong: Shandong Education, 2007.

3. Gan C. The Strategy of Transforming Students with Learning Difficulties in Polytechnic Schools [J]. Yichun Institute Journal, 2009, 8(4).

4. Zhang L., Surveys to Learning Difficulty Cases of Polytechnic School Students[J]. Vocational Education Research, 2008, 6 (9).

5. Wang C., H. Xin. Psychological Trouble of Underachievers and Solutions[J]. Education Exploration, 2003(4):84.

6. Huang W., Y. Wu. Analysis of Learning Difficulties of Polytechnic School Underachievers and Research to Teaching Strategy[J]. China Occupational Skills Education, 2002, 10 (3):20-22.

7. Zhang S. Analysis and Strategy to Polytechnic School Students' Classroom Problem Behaviour Analysis and Countermeasures[D]. Jiangsu: Suzhou University, 2011. 